[Agr. Biol. Chem., Vol. 27, No. 7, p. 526 529, 1963]

\title{
Nucleosides and Related Substances
}

\section{Part I. Synthesis of Pyrimidine Nucleosides via Trichloroacetylsugars*}

\author{
By Konoshin Onodera and Hirokazu Fukumi
}

Biochemical Laboratory, College of Agriculture, Kyoto University, Kyoto

Received March 22, 1963

\begin{abstract}
A novel method is described for the synthesis of pyrimidine nucleosides. 1- $\beta$-D-Glucopyranosyl-, 1- $\beta$-D-xylopyranosyl-, and 1- $\beta$-D-ribopyranosyl-uracils were prepared in good yields by the condensation of uracil with 1-O-trichloroacetyl-2,3,4,6-tetra-O-acetyl- $\alpha$-D-glucopyranose, 1-O-trichloroacetyl-2,3,4-tri-O-acetyl- $\alpha$-D-xylopyranose, and 1-O-trichloroacetyl-2,3-4-tri-Oacetyl- $\boldsymbol{\alpha}$-D-ribopyranose, respectively. Glucosyl- and xylosyluracils were prepared under the reaction conditions similar to those used in the Hilbert-Johnson method, whereas the synthesis of ribosyluracil was carried out by the fusion procedure of the reactants.
\end{abstract}

Since the first synthesis of glucosylpurines was reported by Fischer ${ }^{1)}$, this procedure has widely been used for the synthesis of purine and pyrimidine nucleosides. Todd et al.2) improved and developed the Fischer method in which acylohalogenosugars were allowed to react with heavy metal salts of pyrimidine or purine bases. The Hilbert-Johnson method $^{3)}$ similarly involves acylohalogenosugars for the synthesis of pyrimidine nucleosides, except that the reaction is carried out by fusion. Purine deoxyribonucleoside was synthesized by Fletcher, Jr.4) with use of diisopropyl dithioacetal of 2-deoxy-D-ribose. Recently, a method has been reported by Sato et al.5) for the synthesis of purine nucleo-

* Presented at the Annual Meeting of the Agricultural Chemical Society of Japan, Sendai, April 27, 1962.

1) E. Fischer and B. Helferich, Ber., 47, 210 (1914).

2) J. Davoll, B. Lythgoe and A.R. Todd, J. Chem. Soc., 1948, 967 ; J. Davoll and B.A. Lowy, J. Am. Chem. Soc., 73, 1650 (1951); J.J. Fox, N. Yung, I. Wempen and I.L. Doerr, ibid., 79, 5060 (1957).

3) G.E. Hilbert and E.F. Jansen, ibid., 58, 60 (1936); G.E. Hilbert and T.B. Johnson, ibid., 52, 4489 (1930); G.A. Howart, B. Lythgoe and A.R. Todd, J. Chem. Soc., 1947, 1052.

4) G. Pedersen and H.G. Fletcher Jr., J. Am. Chem. Soc., 82, 5210 (1960).

5) T. Sato, T. Shimadate and R. Ishido, Nippon Kagaku Zasshi, 81, 1440 (1960). sides, in which fully acetylated sugars are let react by fusion with the bases, and more recently Schramm et al.6) have reported the synthesis of purine and pyrimidine nucleosides by the condensation procedure of free sugars with bases in dimethylformamide, using polyphosphoric acid ethyl ester as a catalyst. Thus, it is apparent that acylohalogenosugars are used in most cases as the starting materials, and that pyrimidine nucleosides are able to be synthesized only by either the Hilbert-Johnson or the Schramm method in rather poor yields.

It is also noted that the procedures of Sato ${ }^{5)}$ and Shimadate ${ }^{7)}$ give purine nucleosides in good yields but are not yet reported to be applicable to the synthesis of pyrimidine nucleosides, and that the procedure developed by Schramm still has some difficulties in the synthesis of pyrimidine nucleosides.

Acylohalogenosugars are easily accessible compounds but are generally unstable. In

6) G. Schramm, H. Grötsch and W. Pollmann, Angew. Chem., 74, 53 (1962).

7) T. Shimadate, Nippon Kagaku Zasshi, 82, 1268 (1961). 
this connection, it is desired to develop a novel procedure to synthesize pyrimidine nucleosides which have hitherto been less ready to be prepared.

1-Trichloroacetylsugars were reported by Karasawa to be useful for the synthesis of aryl-N-cellobioside ${ }^{8)}$ as well as of phenol glycosides ${ }^{9}$. He reported that the condensation in alcoholic medium of the reactants produced aryl $a$-N-cellobioside, whereas that by fusion produced aryl $\beta$-N-cellobioside.

It has long been known that in the Helferich procedure for synthesizing O-glycosides ${ }^{10)}$ the stereospecificity of the glycosidic linkage takes place according to the catalyst used. However, in the case of the synthesis of nucleosides $^{5,7)}$ by the fusion procedure, the configuration of the anomeric carbon of the acetylated sugars has the influence on the yields of nucleosides. Thus, with use of $p$ toluenesulfonic acid as a catalyst $\beta$-acetate gives better yields than does $a$-acetate, whereas with zinc chloride $a$-acetate gives better yields than does $\beta$-acetate ${ }^{7}$.

It is generally accepted that the nucleosides prepared by the procedures of Hilbert-Johnson and of Fischer-Helferich are of C-1,2 trans-configuration regardless of the anomeric configuration of the starting materials, acylohalogenosugars. A hypothesis ${ }^{11)}$ (the trans rule), proposed by Tipson and advanced by Baker et al., is to explain the stereospecific control of the nucleosidic linkage formed by the reaction of acylohalogenosugars with heavy metal salts of purine (or pyrimidine) bases. Furthermore, Khorana ${ }^{12)}$ has described that the acyl substituent of the hydroxyl

\footnotetext{
8) I. Karasawa and R. Onishi, J. Agr. Chem. Soc. Japan, 35, 920 (1961).

9) I. Karasawa and R. Onishi, ibid., 35, 704 (1961)

10) B. Helferich and S.R. Petersen, Ber., 68, 790 (1935).

11) W. Pigman, "The Carbohydrates", Academic Press Inc. (New York), 1957, p. 188.

12) G.M. Tener and H.G. Khorana, J. Am. Chem. Soc., 79, 437 (1957); R.S. Wright, G.M. Tener and H.G. Khorana, ibid., 80, 2004 (1958).
}

group at C2 of acylohalogenoribose has the net effect of shielding one side of the furanose ring. The protecting effect of the acyl group has also been discussed by Gorin ${ }^{13)}$ for the synthesis of methyl glycosides as well as disaccharides.

It appears that 1-trichloroacetylsugars behave in the synthesis of nucleosides not like acylohalogenosugars but like acetylated sugars. It was therefore considered that 1-trichloroacetylsugars might be interesting starting materials from the view-point of stereospecificity of the nucleosidic linkage.

1-O-Trichloroacetyl-2,3,4,6-tetra-O-acetyl - $a$ D-glucose (I) and 1-O-trichloroacetyl-2,3,4-triO-acetyl-a-D-xylose (IV) were severally condensed under fusion conditions with 2,4dialkoxypyrimidine ${ }^{14)}$ to give 1 -(tetra-Oacetyl- $\beta$-D-glucopyranosyl) - 4-methoxy- $2(1 \mathrm{H})$ pyrimidinone (II) and 1 - (tri-O-acetyl- $\beta$-Dxylopyranosyl)-4-ethoxy-2 $(1 \mathrm{H})$-pyrimidinone (V) in the yields of 16.8 and $14.8 \%$. The reaction of 1-O-trichloroacetyl-2,3-4-tri-Oacetyl-a-D-ribose (VII) with 4-ethoxy-2 (1 H)pyrimidinone $^{15)}$ with $p$-toluenesulfonic acid as a catalyst gave 1-(tri-O-acetyl-D-ribopyranosyl) -4-ethoxy-2 (1 H) -pyrimidinone (VIII), which was deacetylated to give 1-ribosyluracil (IX) in the yield of $13.8 \%$.

\section{EXPERIMENTAL ${ }^{16)}$}

1-0-Trichloroacetyl-2,3,4,6-tetra-O-acetyl- $\alpha$-D-glucose (I). 1-O-Acetyl-2,3,4,6-tetra-O-acetyl- $\beta$-D-glucose (20 g), trichloroacetic acid $(10 \mathrm{~g})$ and carbon tetrachloride $(50 \mathrm{ml})$ were added to $60 \mathrm{~g}$ of phosphorus trichloride, and the suspension was warmed to give a clear solution. After standing overnight at room temperature with exclusion of moisture, the reaction mixture was refluxed gently for about $2 \mathrm{hr}$. The reaction mixture was then concentrated under reduced pressure to a thick sirup to remove $\mathrm{PCl}_{3}$ and $\mathrm{CCl}_{3} \mathrm{COOH}$ as completely as possible. A white gummy substance was obtained and to this was added $10 \mathrm{ml}$ of absolute

13) P.A.J. Gorin, Can. J. Chem., 40, 275 (1962).

14) G.E. Hilbert and T.B. Johnson, J. Am. Chem. Soc., 52, 2001 (1930).

15) G.E. Hilbert and E.F. Jansen, ibid., 57, 552 (1935).

16) All melting points are uncorrected. 
ethanol, and the mixture was shaken with cooling in ice-water to give a clear solution. Cooling in icewater for additional $2 \sim 3 \mathrm{hr}$. resulted in separation of white needles. The crystals were collected by filtration, washed with a small amount of cold ether, and recrystallized from $15 \mathrm{ml}$ of absolute ethanol. Yield, $17.8 \mathrm{~g}(76 \%)$, m.p. $128^{\circ} \mathrm{C} . \quad[\alpha]_{\mathrm{D}}^{15}=+98.0^{\circ} \quad(c$, 2.0, chloroform). The Beilstein reaction was positive. Anal. Found: C, 39.01; H, 3.85; Cl, 21.53. Calcd. for $\mathrm{C}_{16} \mathrm{H}_{19} \mathrm{O}_{11} \mathrm{Cl}_{8}: \mathrm{C}, 38.90 ; \mathrm{H}, 3.88 ; \mathrm{Cl}, 21.55 \%$.

1-(Tetra - 0 - acetyl - $\beta$-D -glucopyranosyl) - 4-methoxy-2 (1 H)-pyrimidinone (II). I $(20 \mathrm{~g})$ was suspended in $30 \mathrm{ml}$ of 2,4-dimethoxypyrimidine $\mathrm{e}^{14}$ and the reaction mixture was shaken for $24 \sim 48 \mathrm{hr}$. at $80 \sim 100^{\circ} \mathrm{C}$. After $2 \sim 4 \mathrm{hr}$., the suspension became a clear solution and, after about one day, solidified to afford a light brown crystalline mass. The solid reaction product was triturated with ether and then collected by filtration. The insoluble substance was recrystallized from $50 \%$ aqueous ethanol. A white crystalline mass was obtained. Yield, $3.2 \mathrm{~g}(17 \%)$, m.p. $218^{\circ} \mathrm{C} . \quad[\alpha]_{\mathrm{D}}^{15}=$ $+46.0^{\circ}$ (c, 2.0, chloroform). Anal. Found: C, 49.83; $\mathrm{H}, 5.14 ; \mathrm{N}, 6.27$. Calcd. for $\mathrm{C}_{19} \mathrm{H}_{24} \mathrm{O}_{11} \mathrm{~N}_{2}$ : C, 50.00; $\mathrm{H}, 5.26$; $\mathrm{N}, 6.14 \%$.

1- $\beta$-D-Glucopyranosyluracil (III). II (200 mg) was deacetylated with $4 \mathrm{ml}$ of $5 \%$ methanolic hydrogen chloride in the usual procedure. The preciptated product was recrystallized from a small amount of hot water. Yield, $108 \mathrm{mg}(90 \%)$, m.p. $203^{\circ} \mathrm{C} . \quad[\alpha]_{\mathrm{D}}^{15}=$ $+28.0^{\circ}$ (c, 0.73, water). Anal. Found: C, 43.55; $\mathrm{H}$, 5.20; N, 9.98. Calcd. for $\mathrm{C}_{10} \mathrm{H}_{14} \mathrm{O}_{7} \mathrm{~N}_{2}: \mathrm{C}, 43.80 ; \mathrm{H}$, $5.15 ; \mathrm{N}, 10.22 \%$. This substance showed characteristics of the nucleosides. The ultra violet absorption spectrum showed maximum at $260 \mathrm{~m} \mu$, minimum at 230 $\mathrm{m}_{\mu}$ (pH 7.0 in water).

1-0-Trichloroacetyl-2,3,4-tri - 0-acetyl - $\alpha$-D - xylopyranose (IV). 1-O-Acetyl-2,3,4-tri-O-acetyl- $\beta$-D-xylopyranose $^{17)}(18 \mathrm{~g})$, trichloroacetic acid (11 g) and carbon tetrachloride $(60 \mathrm{ml})$ were added to $60 \mathrm{~g}$ of phosphorus trichloride and the mixture was refluxed gently for about $3 \mathrm{hr}$. with exclusion of moisture. The reaction mixture was then concentrated under reduced pressure to remove $\mathrm{PCl}_{3}$ and excess of $\mathrm{CCl}_{3} \mathrm{COOH}$ as completely as possible. The obtained white gummy substance was triturated with ether and the ether layer was removed by decantation. To the residue

17) C.S. Hudson and J.M. Johnson, J. Am. Chem. Soc., 37, 2748 (1915). was added a small amount of absolute ethanol and the residue was dissolved with cooling in an ice-water bath. Allowing to stand for $2 \sim 3 \mathrm{hr}$. in an ice-water bath resulted in the separation of white needles. The crystalline mass was collected by filtration, washed with a small amount of cold ether, recrystallized from absolute ethanol. Yield, $10.5 \mathrm{~g} \mathrm{(40 \% ),} \mathrm{m.p.}$ $108^{\circ} \mathrm{C}$. $[\alpha]_{\mathrm{D}}^{13.5}=+91.1^{\circ}$ (c, 1.33, chloroform). Anal. Found: $\mathrm{C}, 37.09 ; \mathrm{H}, 3.65 ; \mathrm{Cl}, 25.36$. Calcd. for $\mathrm{C}_{13} \mathrm{H}_{15} \mathrm{O}_{9} \mathrm{Cl}_{3}$ : C, 37.01; $\mathrm{H}, 3.56 ; \mathrm{Cl}, 25.27 \%$. The Beilstein reaction was positive.

1-(Tri-0-acetyl- $\beta$-D-xylopyranosyl)-4-methoxy- 2 (1 H)pyrimidinone $(\mathrm{V})$. IV (31.5 g) was suspended in $30 \mathrm{ml}$ of 2,4-dimethoxypyrimidine ${ }^{14}$ ) and shaken for $24 \mathrm{hr}$. at $80^{\circ} \mathrm{C}$. The suspension became a clear solution after $2 \sim 3 \mathrm{hr}$. and, after $15 \sim 20 \mathrm{hr}$., it became a light brown paste, which solidified on cooling. The reaction product was triturated with ether and collected by filtration. The precipitate was recrystallized from $50 \%$ aqueous ethanol. Yield, $4.3 \mathrm{~g}(15 \%)$, m.p. $227^{\circ} \mathrm{C}$. $[\alpha]_{\mathrm{D}}^{12.5}=+59.1^{\circ} \quad(c, 1.01$, chloroform $)$. Anal. Found: C, 50.12; $\mathrm{H}, 5.30 ; \mathrm{N}, 7.27$. Calcd. for $\mathrm{C}_{10} \mathrm{H}_{20} \mathrm{O}_{9} \mathrm{~N}_{2}$ : C, $50.00 ; \mathrm{H}, 5.25 ; \mathrm{N}, 7.29 \%$.

1- $\beta$-D-Xylopyranosyluracil (VI). V (3 g) was deacetylated with $54 \mathrm{ml}$ of $5 \%$ methanolic hydrogen chloride in the usual procedure. The preciptate was recrystallized from hot water. Yield, $1.5 \mathrm{~g}(80 \%)$, m.p. $237^{\circ} \mathrm{C}$. $[\alpha]_{\mathrm{D}}^{24}=+21.4^{\circ}(c, 1.87$, water $)$ Anal. Found: C, 41.38; H, 5.42; N, 10.83. Calcd. for $\mathrm{C}_{9} \mathrm{H}_{12} \mathrm{O}_{6} \mathrm{~N}_{2} \cdot \mathrm{H}_{2} \mathrm{O}: \mathrm{C}, 41.22 ; \mathrm{H}, 5.38 ; \mathrm{N}, 10.68 \%$.

1-0-Trichloroacetyl-2, 3, 4-tri-0-acetyl- $\alpha$-D - ribopyranose (VII). 1-O-Acetyl-2,3,4-tri-O-acetyl- $\beta$-D-ribopyranose $^{18)}(6.8 \mathrm{~g})$ was dissolved in a mixture of $20 \mathrm{ml}$ of carbon tetrachloride and $\mathbf{3} \mathrm{g}$ of trichloroacetic acid, and to this solution was added $20 \mathrm{ml}$ of phosphorus trichloride. The reaction mixture was refluxed gently for $3 \sim 4 \mathrm{hr}$. After completion of the reaction, the reaction mixture was concentrated under reduced pressure to a heavy sirup (below $35^{\circ} \mathrm{C}$ ). The sirup was dissolved in chloroform (dried over $\mathrm{P}_{2} \mathrm{O}_{5}$ ) and $5 \mathrm{~g}$ of silver carbonate was added to this solution to neutralize excess of $\mathrm{CCl}_{3} \mathrm{COOH}$ and $\mathrm{PCl}_{3}$. The undissolved substance was filtered off. The filtrate was concentrated under reduced pressure and the sirup was decolorized with active carbon in ether. This solution was concentrated under reduced pressure to a sirup, which was dried over $\mathrm{P}_{2} \mathrm{O}_{5}$ overnight. This

18) P.A. Levene and R.S. Tipson, J. Biol. Chem,. 92, 109 (1931). 
was used directly in the next reaction.

1-(Tri-0-acetyl - $\beta$-D - ribopyranosyl) - 4-ethoxy - 2 (1 H)pyrimidinone (VIII), VII (1 g) and 4-ethoxy-2 (1 H) pyrimidinone $^{15)}(0.6 \mathrm{~g})$ were mixed well and the mixture was melted at $130 \sim 140^{\circ} \mathrm{C}$ in an oil bath. When the reaction mixture melted throughly, a trace of $p$-toluenesulfonic acid was added and the mixture was mixed well. The reaction mixture was kept under reduced pressure with suction. A vigorous evolution of gas occurred at first and, after $15 \mathrm{~min}$., the reaction mixture solidified to a pasty mass. This was kept under the same conditions for additional $30 \mathrm{~min}$., and then extracted with $\mathrm{CHCl}_{3}$. The undissolved substance was filtered off. The filtrate was concentrated under reduced pressure to a heavy sirup. While having been kept in a desiccator over $\mathrm{CaCl}_{2}$, a white substance separated (after two weeks). The infrared absorption spectrum of this sirup was identical with that of the reference compound, which was prepared by the method of J. J. Fox et al. ${ }^{2)}$ This substance was used directly in the next deacetylation procedure.

1- $\beta$-D-Ribopyranosyluracil (IX). One gram of VIII was deacetylated with $5 \%$ methanolic hydrogen chloride in the usual procedure to give white crystals. Yield, $80 \mathrm{mg}$, m.p. over $220^{\circ}$ C. Anal. Found: N, 11.33 . Calcd. for $\mathrm{C}_{9} \mathrm{H}_{12} \mathrm{O}_{6} \mathrm{~N}_{2}: \mathrm{N}, 11.48 \%$.

This substance gave the same $R_{F}$ value as that of authentic 1- $\beta$-D-ribopyranosyluracil, which was prepared by the method of J. J. Fox et al. ${ }^{2)}$ (developing solvents; HCl-isopropanol, $86 \%$ aqueous $n$-butanol). 